\title{
Basic Music Education on the Background of Quality Education
}

\author{
Ling Xu \\ College of Art and Communication, Bohai University, Jinzhou, 121013, China \\ 105432750@qq.com
}

Keywords: quality education; basic music education; problems; countermeasures

\begin{abstract}
Music education plays an important role in quality education, which can improve students' moral cultivation, promote students' physical and mental health, improve students' aesthetic taste and comprehensive quality. According to the existing music education of basic music education without attention, emphasis on music knowledge, aesthetic ability and ignore the identification of extracurricular activities are not standardized, put forward the Countermeasures of music education under the background of quality education. The specific strategies include: the development of social music education, pay more attention to the diversification of music education; music ability to lay a solid foundation, steadily enhance the artistic accomplishment; from "traditional music oriented" to "guide students into music culture; develop the school music activities, enrich the campus music culture life; play the advantages of information technology, to achieve the basic music education innovation.
\end{abstract}

\section{Introduction}

The aim of quality education is to cultivate the high quality talents with all-round development of morality, intelligence, physique and beauty. Music education with aesthetic experience as the core is an important part of quality education. Music education plays an important role in enlightening students' intelligence, cultivating students' sentiment, developing students' imagination and creativity. Music education as a part of basic education, over the years has made considerable progress, but there are still many problems do not adapt to the development of the times, is a weak link in the whole basic education, there is a certain distance away from the requirement of quality education, it is difficult to keep up with the twenty-first Century social economic and educational development pace. Therefore, in the face of opportunities and severe challenges in music education, how to strengthen the construction of music education and promote the development of aesthetic education has become an urgent issue for music educators. According to music education problems, put forward targeted solutions, to promote the overall improvement of the students' music accomplishment, for the basic music education reform put forward reference, indicate the direction for the development of music education of science.

\section{Basic Concept Definition}

This study involves the following three basic concepts:

(1) The quality of education, according to the needs of the development of students and social development, improve the basic quality of the students, respect students' independent consciousness, to develop students' intelligence and potential for the purpose of the education to help students sound personality. The content of quality education includes psychological quality education, aesthetic quality education, cultural quality education and ideological and moral quality. Quality education is the practical needs of social development, to achieve the right to face and deal with their own social environment of all things and the purpose of the phenomenon.

(2) Music education, through the teaching of music knowledge and skills to students, in order to improve the aesthetic level, cultivate their sentiments and broaden their horizons, to promote the development of a comprehensive and harmonious education of students. The aim of music education is to cultivate practical talents with high quality and innovative spirit. Music education through the physical and psychological education of students and inspire students to stimulate the 
imagination, improve the level of aesthetic, and ultimately to improve the overall quality of students.

(3) Basic education, people need basic education in modern society, usually including regular primary school and middle school, is in the growth of people in order to get more knowledge in advance to master the knowledge of basic education is a basic way to have the necessary quality of modern citizens. As a basic project to cultivate talents and improve the quality of the people, it plays an important role in the reform of education in twenty-first Century.

\section{Function of Music Education in Basic Music Education}

Music education plays an important role in quality education, which is manifested in the following aspects[1,2]:

(1) Music education can improve students' moral cultivation. Moral cultivation has a long history in our country. It is the basic content of citizen moral education and the requirement and principle of socialist market economy. To improve students' moral cultivation is not only the foundation of education, but also the need of students' development. Moral education needs to be based on emotion, music can stimulate people's emotions and make moral education work smoothly. Depending on the music melody, beautiful tone and lively rhythm, will draw out students' emotion, subtly infected students, make students imperceptibly to accept the spirit of the noble quality, consciousness or moral sentiments.

(2) Music education can promote students' physical and mental health. Physical and mental health is a state of physical, mental and social adaptation. Music education can make people happy, make the person's inner feelings of sadness, joy and yearning, enrich people's thoughts and feelings, relieve people's emotions, and promote physical and mental health. With the help of music, students can help ease the pressure of learning, while enjoying the beauty of music, physical and mental relaxation. Through the rich and colorful music activities, to promote the concept of collectivism and the formation of a sense of competition, face reality in the face of setbacks, overcome difficulties, unity and cooperation, so that the physical and mental health.

(3) Music education can improve students' aesthetic taste. Aesthetic taste is a kind of aesthetic tendency which is expressed in the way of personal interest. The noble aesthetic taste is an important part of aesthetic education. Music is a beautiful timbre, lively rhythm, tactful melody and rich sound to the dynamics of the image, stimulate people's emotions with its unique style, cultivate people's noble sentiments and aesthetic taste. Practice has shown that, often with healthy music and elegant music as partners, can make people exciting, improve aesthetic taste, form a good aesthetic consciousness, and create a beautiful behavior.

(4) Music education can improve students' comprehensive quality. To promote the comprehensive and healthy development of students, to further promote quality education, to improve the overall quality of students, and to improve the quality of education, is one of the goals of the basic education reform in the new period. The music involves various disciplines, with strong artistic expression, sound and emotion, but also with a strong sense of rhythm, norm, society, life, culture and folk customs interpretation. Music education can feel the cultural mainstream of the country and the times, deepen the understanding of history and culture, enhance the ability to comprehend the beauty, and improve the comprehensive cultural literacy.

\section{Existing Problems in Basic Music Education}

With the reform and development of quality education, basic music education has been paid attention to, and has made certain achievements. But there are also many problems, outstanding performance in the following areas [3,5]:

(1) Music education is not taken seriously. Although the national promotion of quality education, but also just stay in the concept level, the school has only done teaching, not really "education", ignoring the aesthetic ability of students and the cultivation of music quality. Many school leaders are not fully understand the spirit of education reform, enthusiasm is not high, has been using the 
old educational ideas, can not keep up with the development trend of education. Compulsory education teaching objectives and teaching syllabus of music teaching did not require specific indicators, the influence of exam oriented education, the school enrollment rate is still the focus of attention, lack of understanding of music education, can not guarantee long-term music class rate.

(2) Emphasis on imparting knowledge of music. The basic music education are a lot of "cramming method of teaching", students receive music knowledge passively, boring. "The new music curriculum standard" put forward clearly, music education not to cultivate students to be a musician, but through a variety of ways to guide the students to sound, so that students can actively participate in various musical activities, stimulate interest in learning music in a variety of activities, to enable students to develop a good habit of lifelong love and appreciation of music and music wish. Therefore, from the "technology" to "art" education, the knowledge of music teaching in the secondary position, focusing on the development of music quality.

(3) Neglect the cultivation of aesthetic discrimination. The ability of music appreciation is the aesthetic activity in the process of perceiving music. Music aesthetics is an important part of the whole art of music. In the face of the complex and complex reality of music culture and the good and bad music environment, the ability to identify the music aesthetic is particularly important. The students in music appreciation just stay in the "sound perception" not perfect psychological state, not from the music language completely feel the music, do not understand the content and form of works, not experience emotional content and artistic works have given thought from philosophy, it is difficult to get the appreciation ability and aesthetic taste of the deep.

(4) Extracurricular activities are not standardized. Extracurricular music activities refer to all kinds of music activities outside the classroom, which is an important part of school music education. School music education includes two parts: classroom music teaching and extracurricular music activities. The music teacher's duty is to complete the teaching task, but also to organize extracurricular music activities. At present, the extracurricular music activities are utilitarian and imbalance, some students are subject to "honor" by participating in extracurricular activities, some schools more music competitions, lack of musical activities for all students.

\section{Countermeasures of Basic Music Education on the Background of Quality Education}

Aiming at the existing problems of basic music education, the basic music education theory, combined with national policies and regulations and draw lessons from the typical experience of developed countries, put forward the Countermeasures of music education under the background of quality education is as follows[6-10]:

(1) Development of social music education, pay attention to the diversity of music education. School music education is a clear teaching objectives and teaching content, according to a certain direction to develop students' education, is a Comprehensive popularization education. Social music education level is broad, including students, youth, old age and other social groups, interest based knowledge. The development of social music education can start from the following aspects: first, establish of specialized social music education and management institutions, regulate social music education music education target, take the students as the essence, cultivate students' aesthetic ability and good sentiment; second, strengthen the social education institutions music teachers professional skills, and constantly strengthen their music learning; three, avoid social music education single mode, pay attention to cultivate students' interest, and increase the music literacy class. It is very good for the development of basic music education to improve the diversity of basic music education.

(2) Strengthening the foundation of the music, and steadily improve the artistic quality. Adhere to the ability to adhere to the basic music, abandon the music to learn the general contact. Focus on the cultivation of students a keen sense of hearing feeling ability, kinesthetic response ability and perceptual comprehension ability; basic music knowledge and skill structure optimization, pay attention to music works retain repertoire of reserves and update, attention to appreciate classical music works the connotation of experience, basic ability and artistic accomplishment of lifelong development of students participate in music activities required, promote other intelligence 
development and links. Adhere to the artistic accomplishment, use long-term, comprehensive, find the vision, stimulates the student to participate in music learning deep desire, pay attention to the interests and habits to cultivate; pay attention to independent creation ability, social practice ability and self inquiry desire to develop, cultivate outstanding talent, improve the aesthetic taste and aesthetic quality, to promote students' artistic accomplishment and actively participate in social aesthetic life and meet the needs of the society as an important standard to measure the quality of music education in schools, encouraging the students to participate in extracurricular music activities, will tempering, the cultivation of virtue, comprehension of beauty and taste traditional and social integration, promote the cultivation of innovative talents, reform mode, creating new situation of quality education.

(3) From the" traditional music work" to "guide the students into the music culture". China's current basic music education, the basic face to "music works". This is the defect of the music education in our country, from the long-term development perspective, isn't conducive to the healthy development of music education. Specific solutions: first, the correct understanding of pop music, changing the attitude of pop music, introducing appropriate pop music into the classroom. The introduction of good pop music into the classroom, interlude with the traditional folk music, increase the students' interest in music and hobbies, not only meet the psychological needs of students, but also ease the contradiction between popular music and music classroom; second, introduce the new music genre to the students. Music culture is a dynamic development, each time a new music content will appear. In the music media, these new features are clearly reflected in these new types of music culture should let the students have a certain understanding; Three is the introduction of other related music and cultural knowledge. It is necessary to introduce the knowledge of other related music culture, because the music culture is not only the spirit, but also the material system. So students should have a comprehensive music culture, but also deal with the material culture to do a certain introduction.

(4) Explore the music activities outside the school, enrich the cultural life of the campus music. Using Carry out a variety of extracurricular activities, students' special talents and expertise will be timely discovery, excavation, and get the right guidance and training. First, actively promote the development of a variety of extra-curricular activities. Encourage teachers organize a variety of music groups and interest groups, find and train the backbone of the music. Strengthen the communication between the school and teachers, make music life more rich, not only enrich the students' learning life, cultivate the students' team consciousness, but also promote the development of campus music culture; and then hold all kinds of music competitions, encourage students to enter the music. It's an important way to promote the students' ability to create more opportunities for students to create more opportunities for students to create more opportunities for students. Finally, the creation of good music environment, to encourage students to create music. Including the creation of auditory environment and visual environment, equip with the necessary equipment for students' practical activities.

(5) Giving full play to the advantages of information technology to realize the innovation of basic music education. The information technology education in multimedia teaching environment is supported by computer and network technology, student-centered and teacher centered teaching mode, teaching content to teach students information, to cultivate students' information literacy, learning ability, cooperation ability and innovation ability as the goal. The basic music education in the information age is a comprehensive, efficient and three-dimensional music teaching mode under the information environment. The information of music teaching environment, provides the massive music teaching resources, can maximize the initiative and enthusiasm of students, can carry out individualized teaching, and collaborative teaching, can also be "individual" and "collaboration" combine. This teaching mode can provide rich and colorful graphic audio-visual and three-dimensional interactive teaching interface, with large-scale music knowledge base of art students associative thinking and information base, and experiential and exploratory learning to create favorable conditions to achieve active learning for students to experience music, music, enjoy music and music creation, self realization the acquisition of knowledge, self renew and create new 
knowledge goals. To sum up, the basic music education in information age has the following characteristics: massive music education resources, stimulate interest in learning, deeply understand the connotation of the works, accurate representation of timbre, genre and creative spirit, improve the ability to appreciate.

\section{References}

[1] W. X. A, "Music Training in Character Education," JournaI of Baoshan Teachers' CoIIege, vol. 25, no. 1, pp. 89-92, 2006.

[2] Baidu Wenku, "Comprehensive development of students' comprehensive quality," https://wenku.baidu.com/view/8c1cda2827284b73f242508e.html, 2017-3-2.

[3] M. R. Wang, "Analysis on the present situation of Chinese Music Education," Northern Music, vol. 35, no. 24, pp. 180-180, 2015.

[4] D. Wang, "Analysis on the problems and Countermeasures of basic music education in China," Big stage, vol. 58, no. 3, pp. 192-193, 2015.

[5] W. S. Wang, "Problems and Countermeasures of basic music education," The World of Music, vol. 63, no. 7, pp. 6-7, 2010.

[6] D. G. Zhao, "Problems and solving strategies of basic music education in China," Big stage, vol. 55, no. 2, pp. 178-180, 2012.

[7] H. S. Xu, "The current situation and basic strategies of the reform of the basic music education curriculum in China," Journal of the Central Conservatory of Music, vol. 32, no. 4, pp. 106-113, 2011.

[8] Baidu Wenku, "Music Education under the background of information technology teaching," https://wenku.baidu.com/view/8c1cda2827284b73f242508e.html, 2017-3-2.

[9] M. Z. Wang, "The practice and exploration of the integration of information technology and music education," Industrial \& Science Tribune, vol. 8, no. 11, pp. 183-184, 2013.

[10] A. J. Zhang, "The present situation and Countermeasures of the reform of basic music education in China," Science \& Technology Information, vol. 14, no. 8, pp. 105-106, 2016. 